\title{
Using Drug Overdose Syndromic Surveillance Data to Impact Local Public Health Action
}

\author{
Mandy Billman* and Kayley Dotson \\ Indiana State Department of Health, Indianapolis, IN, USA
}

\section{Objective}

The overall objective of this session is to discuss opportunities to use drug overdose syndromic surveillance (SyS) data to encourage action among local public health partners.

After this roundtable discussion, participants will be able to:

-Identify opportunities to promote use of drug overdose SyS data to their health partners.

-Plan for potential drug overdose public health interventions.

-Develop relationships with roundtable attendees to continue the conversation and sharing of ideas about use of drug overdose SyS data.

\section{Introduction}

Since 2008, drug overdose deaths exceeded the number of motor vehicle traffic-related deaths in Indiana and the gap continues to widen ${ }^{1}$. As the opioid crisis rages on in the United States the federal government is providing funding opportunities to states, but it often takes years for best practices to be developed, shared, and published.

Indiana State Department of Health (ISDH) has developed a standard process for monitoring and alerting local health partners of increases in drug overdoses captured in Indiana's syndromic surveillance system (ESSENCE). ISDH is launching a pilot project to encourage local partners to start a conversation about overdose response capabilities and planning efforts in their community. Other states have published articles about drug overdose syndromic surveillance (SyS) data being used to inform local public health action, however, the local overdose response activity details were vague $^{2,3}$. With the opioid crisis continuing to spiral out of control in the United States, it is imperative to work together as local, state, and national partners to find potential solutions to this crisis.

\section{Keywords}

Opioid; Drug Overdose; Syndromic Surveillance; Local Public Health Response; ED data

\section{References}

${ }^{1}$ Overdose Prevention [Internet]. Indianapolis: Indiana State Department of Health; 2017. Indiana Special Emphasis Report: Drug Overdose Deaths 1999-2015; August 2017. [cited 2017 Sept 25]. Available from: http://www.in.gov/isdh/files/2017_SER_Drug_Deaths_Indiana. pdf

${ }^{2}$ Daly E, Dufault K, Swenson D, Lakevicius P, Metcalf E, Chan B. Use of emergency department data to monitor and respond to an increase in opioid overdoses in New Hampshire, 2011-2015. Public Health Rep. 2017; 132(suppl): 73S-79S. Available from: https://www.ncbi.nlm. nih.gov/pubmed/?term $=28692390$

${ }^{3}$ Ising A, Proescholdbell S, Harmon K, Sachdeva N, Marshall S, Waller A. Use of syndromic surveillance data to monitor poisonings and drug overdoses in state and local public health agencies. Inj Prev. 2016 Apr; 22 Suppl 1: i43-9. Available from: https://www.ncbi.nlm.nih. gov/pubmed/?term $=27044495$

\section{*Mandy Billman}

E-mail: abillman@isdh.in.gov 